\title{
SURGICAL MANAGEMENT OF TIBIAL SHAFT FRACTURE BY INTRAMEDULLARY INTERLOCKING NAILING IN MIMS - A RETROSPECTIVE STUDY
}

\author{
Pandarinath Ashwathnarayanarao ${ }^{1}$, Amaradeep Govindappa²
}

${ }^{1}$ Assistant Professor, Department of Orthopaedics, Mandya Institute of Medical Sciences, Mandya. ${ }^{2}$ Assistant Professor, Department of Orthopaedics, Mandya Institute of Medical Sciences, Mandya.

\begin{tabular}{l}
\hline ABSTRACT \\
\hline BACKGROUND \\
The management of tibial shaft fracture has always held a particular interest for orthopaedic surgeons. Not only they are \\
relatively common, but also they are difficult to treat. The goal of the study was to find out safe and effective management of fracture, \\
early mobility of patient, short stay in hospital.
\end{tabular}

METHOD

This retrospective study from January 2011 - December 2011, 20 patients were treated by closed IM ILN.

\section{RESULTS}

There were 13 RTA (60.5\%), 5 self-fall (20.5\%) and 2 assault (10\%). Average healing time was 18-20 weeks; 15 healed in 18 weeks (75\%) and the rest in between 20-24 weeks (25\%).

\section{CONCLUSION}

Study showed IM ILN tibia in shaft fracture provides early mobility, reduces hospital stay and union of fracture without joint stiffness and other complications.

\section{KEYWORDS}

Fracture shaft tibia, Intramedullary Interlocking nailing (IM ILN).

HOW TO CITE THIS ARTICLE: Ashwathnarayanarao P, Govindappa A. Surgical management of tibial shaft fracture by intramedullary interlocking nailing in MIMS - a retrospective study. J. Evolution Med. Dent. Sci. 2016;5(40):2445-2447, DOI: $10.14260 /$ jemds/2016/570

\section{INTRODUCTION}

Tibia by its location exposed to frequent injuries. Treatment of tibial shaft fracture in adult is a challenge to orthopaedic surgeons due to poor soft tissue coverage, poor blood supply, anticipated complications like compartment syndrome, neurovascular injuries, infection, non-union, delayed/malunion.

Acceptable treatment goal for fracture tibial shaft is union maintaining normal length, normal alignment without rotational deformity, normal joint movement and reduced hospital stay. Charnley. ${ }^{1}$ in 1961 said we have a long way to go before best method of treating fracture tibial shaft can be stated with finality. IM nailing. ${ }^{2}$ (Lotte, Ender) has been used for long time for fixation of tibia. As there are varieties of treatment for fracture of tibial shaft, it is very difficult to manage by single treatment method. Over last couple of decades, management of tibial shaft fracture has oscillated like a pendulum of clock from non-surgical to surgical. In the past, tibial shaft fracture was managed by immobilization by plaster cast. ${ }^{3}$ Thereafter, functional braces of Sarmiento. ${ }^{4}$ was used. First use of IM ILN. ${ }^{5}$ was by Lambotte in 1907.

In 1974, semi-rigid triflanged. 6 IM nailing was introduced for closed nailing without reaming. In 1960s-

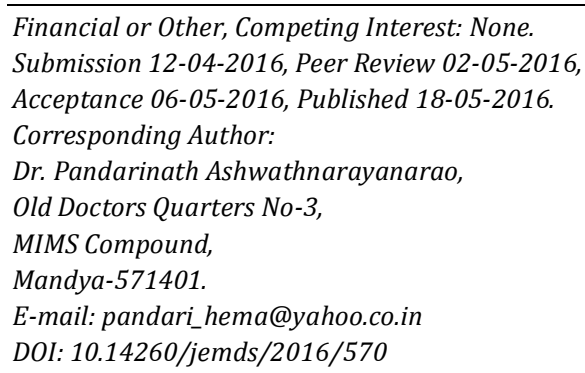

1970s, external fixation. ${ }^{7}$ was most popular. Plating resulted in high incidence of non-union, infection and fixation failure.8-9 IM ILN closed introduction minimized the chance of infection. ${ }^{10}$, promotes early union, regain early activity. ${ }^{11}$ and reduced exposure and operative trauma. ILN is an IM nails that are fixed to bones with bolts at both ends. Closed tibial nailing is a procedure in which closed reduction of fracture site done without opening fracture site and IM ILN is introduced through a tibial tuberosity and fixed with bolts. Closed tibial ILN was initially used without reaming technique. ${ }^{12}$ Due to delayed union, reaming technique was started. C-Arm is essential and is used to do locking by free hand technique.

\section{MATERIALS AND METHODS}

This retrospective study was carried in Department of Orthopaedics, MIMS, Mandya, mainly during January 2011December 2011. A total number of 60 patients were reviewed having tibial fractures. About 25 patients having tibial proximal and distal fractures and 15 patients having open tibia fracture grade 3 were excluded. Out of 60 patients, 20 patients aged from 23 years to 85 years having closed fracture shaft tibia, location of fracture $7 \mathrm{~cm}$ below knee joint and $4 \mathrm{~cm}$ above ankle joint, duration of fracture less than 4 weeks Type 1 and Type 2 open fractures were reviewed. There were 16 male and 4 female patients; 5 have sustained fracture following self-fall, 2 due to assault and rest sustained fracture following RTA were included accordingly to inclusion and exclusion criteria. After inclusion criteria, patients were included in the study. Patient's history, physical examination, informed consent, investigations were obtained and standard IM ILN procedure was carried out. Nails used were of 8-11 mm diameter and 30$36 \mathrm{~mm}$ long stainless steel implant. After intramedullary reaming nailing was done, antibiotics were given for 5 days. 
Patients were mobilized after 24-48 hours depending on patient's threshold for pain. Patient was allowed to toe touch, weight bearing partially in the immediate postoperative period and full weight bearing after 2 weeks. Patients were called for follow-up at 4, 8, 16, 24 weeks and were assessed.

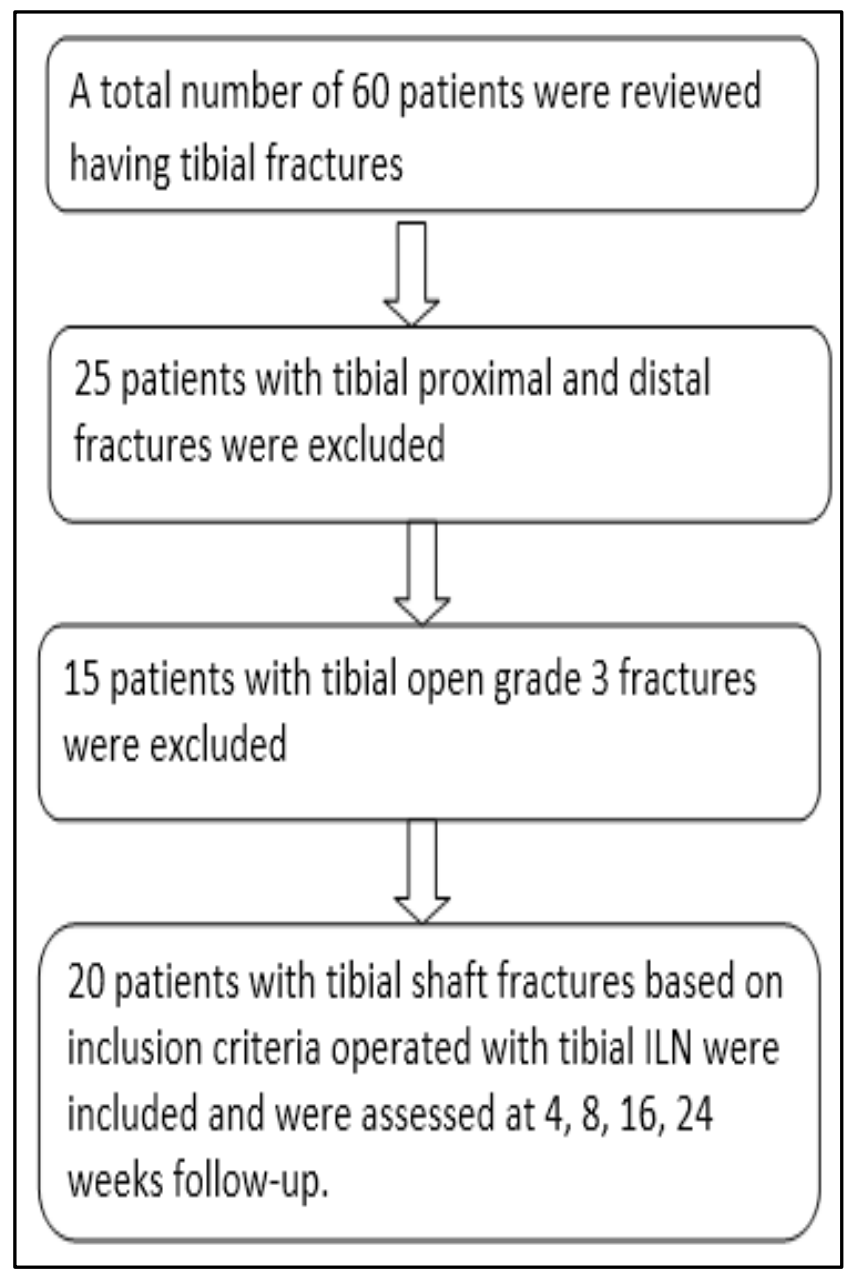

Fig. 1: Indicating Methodology/Study Design

\section{RESULTS}

Total number of patients were 20. One patient died during course of follow-up and was followed up to 24 weeks. Age range was between 23 years - 83 years and average age 35 years; 16 were male (80\%), 4 were female (20\%). Average BMI was $22.5 \mathrm{~kg} / \mathrm{m}^{2}$. There was right sided fracture in 12 patients $(60 \%)$ and left sided in 8 patients (40\%). All fractures were midshaft transverse and short oblique fractures. There was 4 Type 1 and Type 2 open fractures (20\%).

There were 13 RTA (60.5\%), 5 self-fall $(20.5 \%)$ and 2 assault (10\%). Average healing time was 18-20 weeks; 15 healed in 18 weeks (75\%) and rest in between $20-24$ weeks $(25 \%)$. Knee pain was observed in 5 patients $(25 \%)$ and relieved with analgesics in a couple of days. All had free ankle movements. One patient developed superficial infection and was treated with antibiotics for 3 weeks. One patient requires dynamization after 16 weeks. All fractures united radiologically and clinically within 18-20 weeks. No other complications were reported.

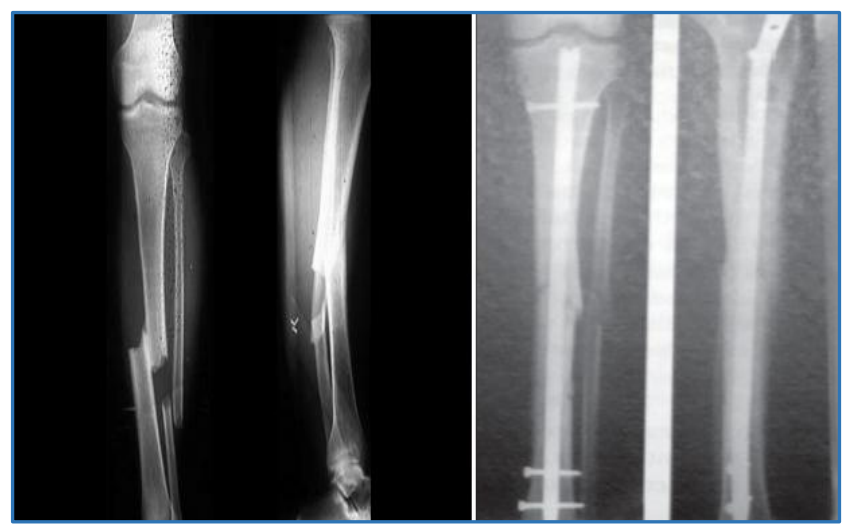

Fig. 2: X-ray Images Depicting Preoperative and United Fracture Operated with ILN

\section{DISCUSSION}

In our study, mean age was 35 yrs. Most common age group for tibial diaphyseal fractures occurring was young adult active male patients. Mode of injury in our study most common was RTA, which was comparable with the other studies. Open fractures in tibia are more common compared to other bony injuries, because of its anatomical reasons. Total no. of patients having open type 2 and 1 was $20 \%$.

Larsen et al ${ }^{13}$ studied 45 patients with reamed ILN in whom average time of healing was 16.7 weeks and 2 malunion. While in our study healing time was 18 weeks with no malunion. Bonville et al ${ }^{14-15}$ studied IM ILN with reaming (Grosse Kempf nail) in 32 patients in whom only one case developed deep infection. While in our study, there is no infection. He concludes that nailing with reaming remains preferred method of treatment of tibial shaft fracture. Valsto et $\mathrm{al}^{16}$, Vidhyadhara et $\mathrm{al}^{17}$ studied fracture healing time and was about 20.1 weeks; while in our study it was 18 weeks. Court Brown et al studied 25 patients with average union time of around 15.4 weeks with no infection, non-union, delayed/malunion. ${ }^{18}$

All had free ankle and knee movements in our study. Bonville et al in another study pointed out that there was normal range of active movements in knee and ankle.

Steinberg 18 and his colleagues studied 64 cases with diaphyseal fractures. They pointed out that 11 (20.4\%) complications related to nailing, $3(5.5 \%)$ complications related to deep and superficial infection, 1 compartment syndrome and shortening of $1 \mathrm{~cm}$, while not reported similar complications in our study.

It is evident from above facts that closed IM ILN is a safe and quite effective method for treatment of tibial shaft fracture with good recovery and without much complications.

\section{CONCLUSION}

Tibial diaphyseal fractures are commonly seen in physically active young people and are commonly seen as a result of road traffic accidents. The method of treatment employing closed intramedullary interlocking nailing to stabilize both principal fragments on the nail is an excellent one for closed fractures and open Type 1 and 2 fractures. The method of intramedullary interlocking nailing is ideal with the excellent results associated with the advantage of rapid rehabilitation and relatively of few complications serves to recommend it for wider use. 


\section{REFERENCES}

1. Charnley J. The closed treatment of common fractures. Edinburg 1961;3rd ed:105.

2. Lottes LO, Lloyd J Hill, Albert Key J. Closed reduction, plate fixation and medullary nailing of fracture of both bones of the leg. J Bone Joint Surg 1952;34(4):861-82.

3. Elis $\mathrm{H}$. The speed of healing after fracture of tibial shaft. J Bone J Surg Br 1952;40(1):42-64.

4. Sarmiento A. A functional below-the-knee brace for tibial fractures a report on its use in one hundred thirty-five cases. J Bone Joint Surg Am 1970;52(2):295-311.

5. Kyle RF. Biomechanics of intramedullary nailing fracture fixation. Orthopaedics 1985;8(11):1356-9.

6. Lottes JO. Medullary nailing of the tibia with the triflange nail. Clin Orthop 1974;105:53-66.

7. Myers SH, Spigel D, Flynn JM. External fixation of highenergy tibia fractures. J Paediatr Orthop 2007;27(5):5379.

8. Janssenn KW, Biert J, Van Kampen A. Treatment of distal tibial fractures: plate versus nail: a retrospective outcome analysis of matched pairs of patients. Int Orthop 2007;31(5):709-14.

9. Tornetta P, Bergman M, Watnik N, et al. Treatment of grade III open tibial fractures a prospective randomized comparison of external fixation and non reamed locked nailing. J Bone joint Surg 1994;76(1):13-9.

10. Niedzwiedzki L. Use of reamed locked intramedullary nailing in the treatment of aseptic diaphyseal tibial nonunion. Ortop Traumatol Rehabil 2007;9(4):384-96.
11. Court-Brown CM, Keating IF, McQueen MM. Infection after intramedullary nailing of the tibia: incidence and protocol for management. J Bone Joint Surg Br 1992;74(5):770-4.

12. Court-Brown CM, Will E, Christie J, et al. Reamed or unreamed nailing for closed tibial fractures a prospective study in tscherne $\mathrm{C} 1$ fractures. J Bone Joint Surg $\mathrm{Br}$ 1996; 78(4):580-3.

13. Larsen LB, Madsen JE, Hoiness PR, et al. Should insertion of intramedullary nails for tibial fractures be with or without reaming? a prospective, randomized study with 3.8 years' follow-up. J Orthop Trauma 2004;18(3):144-9.

14. Bonnevialle P, Cariven P, Bonnevialle N, et al. Segmental tibia fractures: a critical retrospective analysis of 49 cases. Rev Chir Orthop Reparatrice Appar Mot 2003;89(5):423-32.

15. Bonnevialle $\mathrm{P}$, Belumore $\mathrm{Y}$, Foucras L, et al. Tibial fracture with intact fibula treated by reamed nailing. Rev Chir Orthop Reparatrice Appar Mot 2000;86(1):29-37.

16. Vaisto 0 , Toivanen J, Paakkala T, et al. Anterior knee pain after intramedullary nailing of a tibial shaft fracture an ultrasound study of patellar tendons of 36 patients. Orthop Trauma 2005;19(5):311-6.

17. Vidhyadhara S, Sharath KR. Prospective study of the clinic-radiological outcome of interlocked nailing in proximal third tibial shaft fractures. Injury 2006;37(6):536-42.

18. Steinberg EL, Geller DS, Yacoubian SV, et al. Intramedullary fixation of tibial shaft fractures using an expandable nail: early results of 54 acute tibial shaft fractures. S Orthop Trauma 2006;20(5):303-9. 